\title{
CORRECTION
}

View Article Online

View Journal | View Issue

\section{Correction: Understanding the behaviour of different metals in loaded scintillators: discrepancy between gadolinium and bismuth}

Cite this: J. Mater. Chem. C, 2015,

3, 7523

\author{
Guillaume H. V. Bertrand, Jonathan Dumazert, Fabien Sguerra, Romain Coulon, \\ Gwenolé Corre and Matthieu Hamel*†
}

DOI: $10.1039 / \mathrm{c} 5$ tc90119g

www.rsc.org/MaterialsC

Correction for 'Understanding the behaviour of different metals in loaded scintillators: discrepancy between gadolinium and bismuth' by Guillaume H. V. Bertrand et al., J. Mater. Chem. C, 2015, 3, 6006.

Details of two of the references were incorrect. The correct versions of ref. 14 and 26 are given below as ref. 1 and 2 , respectively. The Royal Society of Chemistry apologises for these errors and any consequent inconvenience to authors and readers.

\section{References}

1 N. J. Cherepy, R. D. Sanner, T. M. Tillotson, S. A. Payne, P. R. Beck, S. Hunter, L. Ahle and P. A. Thelin, IEEE Nucl. Sci. Symp. Med. Imaging Conf. Rec., 2012, 1972-1973.

2 V. B. Brudanin, V. I. Bregadze, N. A. Gundorin, D. V. Filossofov, O. I. Kochetov, I. B. Nemtchenok, A. A. Smolnikov and S. I. Vasiliev, Part. Nucl. Letters, 2001, 6, 69-77. 